\title{
Early surgical myocardial revascularization in non-ST-segment elevation acute coronary syndrome
}

\author{
Sebastian V. Rojas ${ }^{1 \#}$, Mai Linh Trinh-Adams ${ }^{1 \#}$, Aitor Uribarri ${ }^{1,2}$, Felix Fleissner ${ }^{1}$, Pavel Iablonskii ${ }^{1}$, \\ Sara Rojas-Hernandez ${ }^{3}$, Marcel Ricklefs ${ }^{1}$, Andreas Martens ${ }^{1}$, Stefan Rümke ${ }^{1}$, Gregor Warnecke ${ }^{1}$, \\ Serghei Cebotari ${ }^{1}$, Axel Haverich ${ }^{1}$, Issam Ismail ${ }^{1}$
}

${ }^{1}$ Department of Cardiothoracic-, Transplantation- and Vascular Surgery, Hannover Medical School, Hannover, Germany; ${ }^{2}$ Department of Cardiology, Complejo Hospitalario de Navarra, Pamplona, Spain; ${ }^{3}$ Department of Anaesthesiology and Intensive Care Medicine, Hannover Medical School, Hannover, Germany

Contributions: (I) Conception and design: SV Rojas, A Haverich, I Ismail; (II) Administrative support: G Warnecke, S Cebotari, A Haverich; (III) Provision of study materials or patients: A Martens, SV Rojas, G Warnecke, S Cebotari, A Haverich, I Ismail; (IV) Collection and assembly of data: SV Rojas, ML Trinh-Adams, A Uribarri; (V) Data analysis and interpretation: SV Rojas, ML Trinh-Adams, A Uribarri, F Fleissner, P Iablonskii, S Rojas-Hernandez, M Ricklefs, S Rümke; (VI) Manuscript writing: All authors; (VII) Final approval of manuscript: All authors.

\#These authors contributed equally to this work.

Correspondence to: Issam Ismail, MD. Department of Cardiothoracic, Transplantation and Vascular Surgery, Hannover Medical School, CarlNeuberg-Str. 130625 Hannover, Germany. Email: Ismail.Issam@mh-hannover.de.

Background: In non-ST-elevation myocardial infarction (NSTEMI) there is no consensus regarding optimal time point for coronary artery bypass grafting (CABG). Recent findings suggest that long-term outcomes are improved in early-revascularized NSTEMI patients. However, it has been stated that early surgery is associated to increased operative risk. In this study, we wanted to elucidate if early CABG in nonST-elevation acute coronary syndrome can be performed safely.

Methods: We performed a monocentric-prospective observational study within a 2-year interval. A total of 217 consecutive patients (41 female, age 68.9 \pm 10.2 , ES II 6.62 \pm 8.56 ) developed NSTEMI and underwent CABG. Patients were divided into two groups according to the time point of coronary artery bypass after symptom onset (group A: $<72$ h; group B: $>72$ h). Endpoints included 6-month mortality and incidence of MACE (death, stroke or re-infarction).

Results: There were no differences regarding mortality between both groups (30 days: group A $2.4 \%$ vs. group B 3.7\%; P=0.592; 6 months: $8.4 \%$ vs. 6.0\%; $\mathrm{P}=0.487$ ). Incidence of MACE in the 6-month followup was also similar in both groups (group A: $9.6 \%$ vs. $9.7 \%, \mathrm{P}=0.982$ ). Regression analysis revealed as independent risk factors for mortality in the entire cohort ES II OR 1.045 (95\% CI: 1.004-1.088). ES II remained an independent prognostic factor in group A OR 1.043 (95\% CI: 1.003-1.086) and group B OR 1.032 (95\% CI: 1.001-1.063).

Conclusions: Early revascularized patients showed a higher level of illness. However, results of early CABG were comparable to those following delayed revascularization. Moreover, EuroSCORE II was determined as independent risk factors for mortality.

Keywords: Myocardial infarction (MI); non-ST-elevation myocardial infarction (NSTEMI); coronary artery bypass grafting $(\mathrm{CABG})$

Submitted Apr 26, 2019. Accepted for publication Aug 20, 2019.

doi: $10.21037 /$ jtd.2019.11.08

View this article at: http://dx.doi.org/10.21037/jtd.2019.11.08 


\section{Introduction}

Myocardial infarction (MI) as acute manifestation of coronary artery disease (CAD) is one of the leading causes of death worldwide (1). As "time is muscle", ongoing ischemia remains a major pitfall in this pathology, causing cardiac cell death with life-threatening arrhythmias and/ or loss of contractility. Therefore, the natural main therapy goal in MI is to reestablish coronary blood flow as soon as possible. However, in non-ST-elevation myocardial infarction (NSTEMI), where ischemia is considered less critical than in ST-elevation myocardial infarction (STEMI), patient management has been traditionally less aggressive regarding time point of revascularization. Furthermore, it has been claimed that delaying coronary artery bypass grafting (CABG) in NSTEMI contributes to decrease the perioperative risk (2-4). Nevertheless recently, long-term outcomes of NSTEMI patients have been investigated in function of their time to intervention, showing both risk and mortality reduction in early revascularized patients (5).

Most of revascularizations are performed by percutaneous coronary interventions (PCI) (6). Indication for CABG is: unsuccessful or unsuitable PCI, cardiogenic shock, combined surgery or severe multivessel disease (7-9). Different studies have shown that CABG in MI can be performed in high-risk patients with good clinical results (10-17). But even if recent studies have shown good results in early CABG (5), clinical experience in this field remains limited and further studies are needed to evaluate safety and potential benefits of early CABG in NSTEMI patients.

\section{Methods}

We performed a prospective observational study including all patients that underwent eGABG with NSTEMI at Hannover Medical School between 2014 and 2016. Patients that required concomitant cardiac surgery were excluded. A total of 217 Patients were enrolled and divided into two groups according to the time lapse between onset of symptoms and revascularization: Group A ( $>72 \mathrm{~h})$ and Group B ( $<72$ h). Heart team met to elucidate on the best choice of revascularization in all cases, according the advice of clinical practice guidelines. All patients were operated as previously described (10). Baseline characteristics are presented in Table 1. Maximum follow-up was 6 months after operation. The investigation conforms to the principles outlined in the Declaration of Helsinki. The local institutional review board approved the study. Postoperative medical care was managed according to usual practice: all patients were treated with one of the antiplatelet agents as well as statins additionally to the other cardiovascular medication needed.

\section{Statistical analysis}

Statistical analysis was performed using SPSS 20.0 (IBM SPSS Statistisics, IBM Corp., Armonk NY, USA). We used unpaired t-test, Fisher's exact test, Pearson's chi-square test and the Kaplan Meier survival estimation for statistical analysis. Univariate and multivariate regressions analyses were also performed. Survival curves were compared applying log rank test. Differences were considered significant at $\mathrm{P}<0.05$. All continuous data are summarized as mean \pm standard deviation (SD).

\section{Results}

\section{Demographics and preoperative data}

Baseline characteristics are summarized in Table 1. A total of 217 patients were included, being $18.4 \%$ females with a mean age of $68.9 \pm 10.2$ years. There were no significant differences regarding means of ES-II between both groups (7.72 \pm 8.91 vs. $6.17 \pm 8.44 ; \mathrm{P}=0.200)$. Groups differed in the following categories: incidence of cardiogenic shock (group A: $22.9 \%$ vs. group B: $6.7 \%$; $\mathrm{P}=0.001$ ), preoperative mechanical circulatory support (group A: $20.5 \%$ vs. group B: $1.5 \% ; \mathrm{P}<0.001$ ), preoperative level of CK (group A: $391 \pm 495 \mathrm{U} / \mathrm{L} v s$. group B: $213 \pm 488 \mathrm{U} / \mathrm{L}, \mathrm{P}=0.010$ ), preoperative level of CK-MB (group A: $46 \pm 42 \mathrm{U} / \mathrm{L} v s$. group $\mathrm{B}: 25 \pm 22 ; \mathrm{P}<0.001)$ and incidence of left main stem disease (LMSS) (group A: $54.2 \%$ vs. group B: $38.1 \%$; $\mathrm{P}=0.020$ ).

\section{Intra- and early postoperative data}

All intraoperative as well as early postoperative data are summarized in Table 2. Most of procedures were performed on-pump. There were differences regarding: postoperative IABP treatment (group A: $19.3 \%$ vs. group $\mathrm{B}: 8.2 \%, \mathrm{P}=0.016$ ), total arterial revascularization (group A: $9.6 \%$ vs. group B: $20.1 \%, \mathrm{P}<0.05)$ and maximum levels of postoperative $\mathrm{CK}-\mathrm{MB}$ (group A: $99 \pm 115 \mathrm{U} / \mathrm{L} v s$. group B: $60 \pm 53 \mathrm{U} / \mathrm{L}, \mathrm{P}=0.001)$. 
Table 1 Baseline characteristics

\begin{tabular}{|c|c|c|c|}
\hline Characteristics & Group $A,<72$ hours, $n=83$ & Group $B,>72$ hours, $n=134$ & $P$ value \\
\hline Female, n (\%) & $17(20.5)$ & $24(17.9)$ & 0.638 \\
\hline Hypertension, n (\%) & $61(73.5)$ & $110(82.1)$ & 0.132 \\
\hline DM, n (\%) & $25(30.1)$ & $46(34.3)$ & 0.521 \\
\hline Smoking, n (\%) & $25(30.1)$ & 45 (33.6) & 0.596 \\
\hline $\mathrm{BMI}\left(\mathrm{kg} / \mathrm{m}^{2}\right)$ & $27.8 \pm 5.2$ & $28.2 \pm 4.5$ & 0.559 \\
\hline COPD, n (\%) & $5(6.0)$ & $9(6.7)$ & 0.840 \\
\hline PVD, n (\%) & $8(9.6)$ & $19(14.2)$ & 0.325 \\
\hline ES II & $7.72 \pm 8.91$ & $6.17 \pm 8.44$ & 0.200 \\
\hline TIMI score $>4$ & $66(79.5)$ & $105(78.4)$ & 0.839 \\
\hline LV-EF (\%) & $48 \pm 11$ & $48 \pm 11$ & 0.937 \\
\hline Cardiogenic shock, n (\%) & $19(22.9)$ & $9(6.7)$ & 0.001 \\
\hline Mechanical support, n (\%) & $17(20.5)$ & $2(1.5)$ & $<0.001$ \\
\hline CK (U/L) & $391 \pm 495$ & $213 \pm 488$ & 0.010 \\
\hline CK-MB (U/L) & $46 \pm 42$ & $25 \pm 22$ & $<0.001$ \\
\hline $\mathrm{CRP}(\mathrm{mg} / \mathrm{dL})$ & $18.7 \pm 31.4$ & $26.6 \pm 39.7$ & 0.158 \\
\hline
\end{tabular}

DM, diabetes mellitus; DL, dyslipoproteinemia; BMI, body-mass-index; COPD, chronic obstructive pulmonary disease; PVD, peripheral vascular disease; MI, myocardial infarction; ES II, EuroSCORE II; TIMI, thrombolysis in myocardial infarction; LV-EF, left ventricular ejection fraction; LMSS, left main stem stenosis.

\section{Outcome during 6-month follow-up}

An overview of results is shown in Table 3. There were no differences between both groups regarding the need of postoperative dialysis (group A: $3.6 \%$ vs. group B 5.2\%, $\mathrm{P}=0.595$ ), the incidence of stroke (group A: $2.4 \%$ vs. group $\mathrm{B}: 3.0 \%, \mathrm{P}=0.802$ ) or re-infarction (group $\mathrm{A}: 3.6 \%$ vs. group B: $3.7 \%, P=0.965)$. Graft occlusion was observed in group A patients (1.2\%) and group B patients (1.5\%), $\mathrm{P}=0.868$. There were no significant statistical differences regarding mortality between both groups. 30-day mortality was: group A: $2.4 \%$ vs. group B: $3.7 \%, \mathrm{P}=0.592$; 6-month mortality was: group A: $8.4 \%$ vs. group B: $6.0 \%, \mathrm{P}=0.487$ (Figure $1 A, B)$. A composite of death, stroke or re-infarction (MACE) showed similar results between both groups (group A: 9.6\% vs. group B: 9.7\%, $\mathrm{P}=0.982)$.

Univariate and multivariate regression analyses were performed for: all patients (Table 4), group A patients (Table 5) and group B patients (Table 6). EuroSCORE II was calculated as independent predictor for mortality in all patients (OR 1.045, 95\% CI: 1.004-1.088). Moreover, ES II once again was shown to be an adequate independent prognostic factor in both; group A OR 1.043 (95\% CI: 1.003-1.086) and group B group B OR 1.032 (95\% CI: 1.001-1.063). A ROC curve was plotted for the EuroSCORE II (area under the curve 0.733) (Figures 1C,2).

\section{Discussion}

PCI remains the gold standard for the majority of 
Table 2 Intra- and early postoperative data

\begin{tabular}{|c|c|c|c|}
\hline Variable & Group $A,<72$ hours, $n=83$ & Group $B,>72$ hours, $n=134$ & $P$ value \\
\hline CBP (min) & $89 \pm 24$ & $94 \pm 39$ & 0.263 \\
\hline Cross-clamp (min) & $43 \pm 15$ & $47 \pm 16$ & 0.078 \\
\hline Number of grafts (n) & $3.2 \pm 0.8$ & $3.1 \pm 0.8$ & 0.471 \\
\hline IABP, n (\%) & $16(19.3)$ & $11(8.2)$ & 0.016 \\
\hline ECMO, n (\%) & $1(1.2)$ & $2(1.5)$ & 0.860 \\
\hline Incomplete revascularisation & $16(19.2)$ & $13(9.7)$ & 0.041 \\
\hline $\mathrm{CK} \max (\mathrm{U} / \mathrm{L})$ & $1,916 \pm 2,013$ & $1,540 \pm 3,181$ & 0.339 \\
\hline ICU stay (days) & $3.6 \pm 4.2$ & $2.5 \pm 4.3$ & 0.076 \\
\hline Total hospital stay (d) & $10.9 \pm 5.9$ & $10.8 \pm 7.7$ & 0.097 \\
\hline
\end{tabular}

OPCAB, off-pump coronary artery bypass grafting; CPB, cardiopulmonary bypass; IABP, intra-aortic balloon pump; ECMO, extracorporeal membrane oxygenation; ICU, Intensive care unit.

Table 3 Outcome

\begin{tabular}{|c|c|c|c|}
\hline Variable & Group $\mathrm{A},<72$ hours, $\mathrm{n}=83$ & Group $B,>72$ hours, $n=134$ & $P$ value \\
\hline Dialysis, n (\%) & $3(3.6)$ & $7(5.2)$ & 0.595 \\
\hline MI, n (\%) & $3(3.6)$ & $5(3.7)$ & 0.965 \\
\hline Graft occlusion, n (\%) & $1(1.2)$ & $2(1.5)$ & 0.868 \\
\hline 6-month-mortality, n (\%) & $7(8.4)$ & $8(6.0)$ & 0.487 \\
\hline MACE-6-month, n (\%) & $8(9.6)$ & $13(9.7)$ & 0.982 \\
\hline
\end{tabular}

MACE, death, stroke or re-infarction.

revascularizations in $\mathrm{MI}$ since it is fast, effective and broadly available $(6,7,18)$. However, when it is feasible, revascularization mode should be based on the severity and distribution of CAD (7). This rule also applies for patients with NSTEMI. Thus, in multivessel disease, patients would take additional benefit from CABG, especially regarding long-term results $(19,20)$. Concerning the right time point of revascularization, there is still an ongoing discussion. However, new recommendations for NSTEMI patients make this decisions dependent on the individual patient's risk (7). Moreover, early surgery may be beneficial to reduce ischemic time of patients and prevent clinical deterioration (21).

Still there are several studies that show CABG soon after acute $\mathrm{MI}$ is associated with high operative mortality and morbidity (22). Surgical difficulties encountered during $C A B G$ in the early phase of acute MI due to edema, induration and fragility of myocardial tissue may partly explain this finding. In this setting, cardiac trauma with abrasive injury can occur even with gentle handling, and the visualization of target vessel and arteriotomy can be challenging, making the precision of coronary anastomoses even more demanding (23). Another strategy to reduce 
A

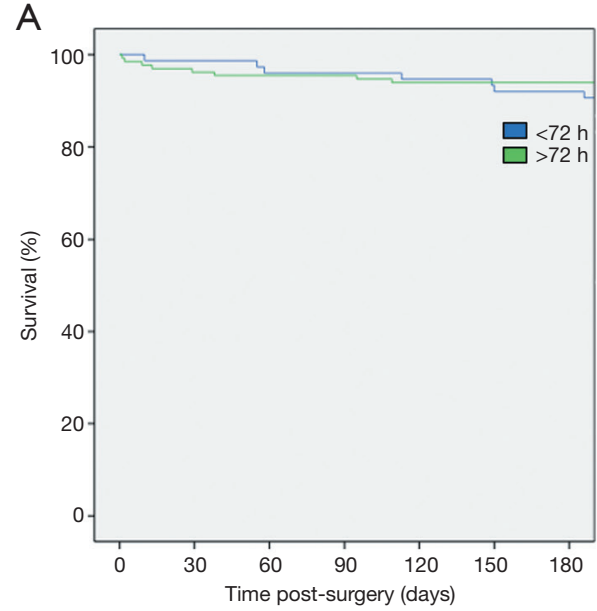

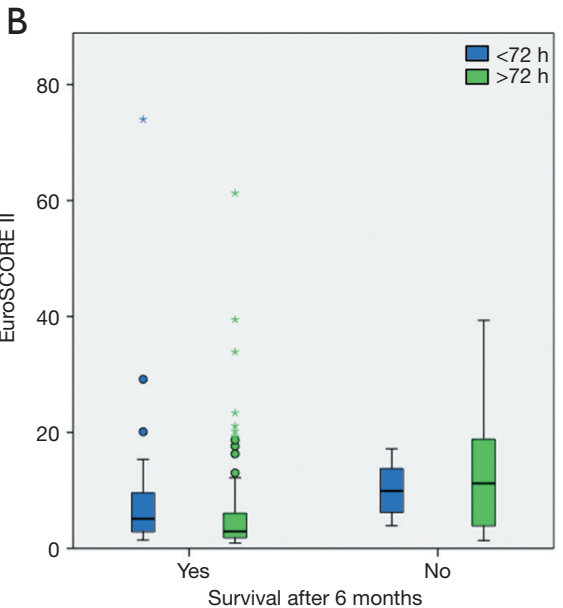

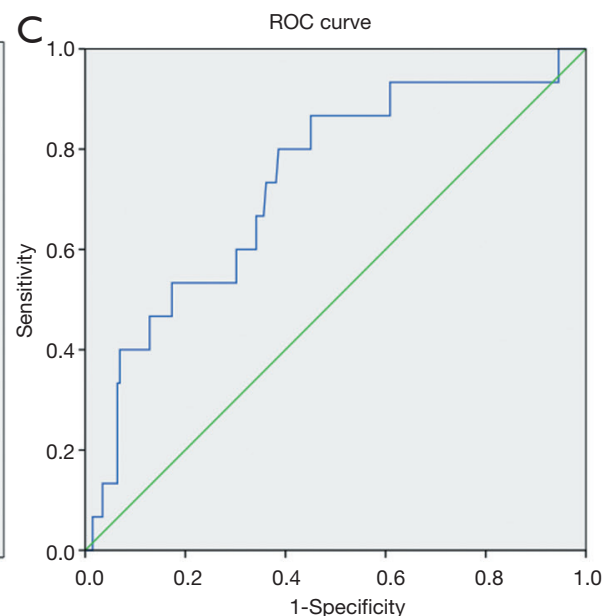

Figure 1 Patients characteristics: (A) Kaplan-Meier estimate of survival, (B) EuroSCORE II comparison in survivors and non-survivors, (C) ROC curve for EuroSCORE II.

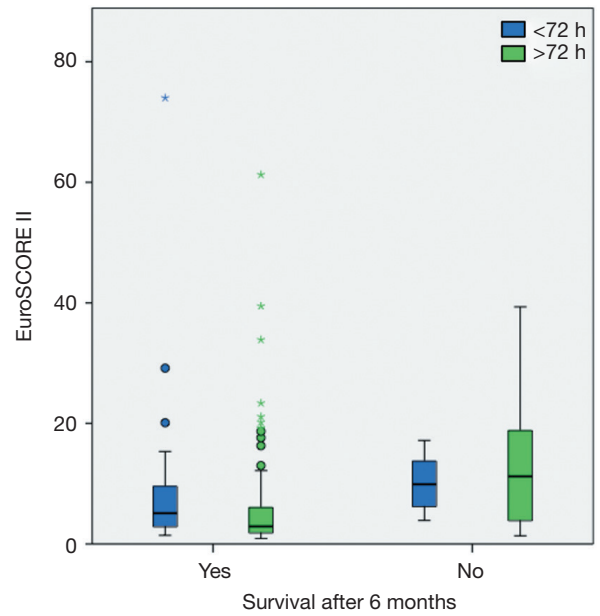

Figure 2 Mortality rate according to EuroSCORE II.

perioperative risk is the discontinuation of antiplatelet therapy.

In the present study we compared NSTEMI patients that underwent CABG following NSTEMI at our institution. Patients were divided into two groups according to time point of revascularization: group A $<72 \mathrm{~h}$, group B $>72 \mathrm{~h}$. Our analysis unveiled that baseline-characteristics of group A patients showed a tendency to higher level of illness with significant higher incidences of preoperative cardiogenic shock, left main stem stenosis and higher preoperative levels of CK and CK-MB. In other words, most critical cases were operated earlier. This is also reflected by the preoperative data: Mechanical support was needed in 20.5\% of group A patients vs. 1.5\% of group B patients. Despite the increased severity of patient mortality and major events in the study period, postoperative outcomes did not differ from late surgery group. Moreover, several of our patients had clinical deterioration days after the initial event needing an emergency surgery. On the other hand, we observed a higher percentage of incomplete revascularization in the group of early surgery that could affect the long-term prognosis in this group of patients; however, increased monitoring is necessary to confirm this.

Although EuroSCORE II models have shown poor calibration with comparatively poor discrimination for emergency cardiac surgery (24), in our study, it predicted successfully mortality in our patients and was not significantly affected by the time point when surgery was performed.

\section{Limitations}

This study has the inherent limitations of observational registries, because the timing of referral for both cardiac catheterization and CABG was left to the discretion of the treating physician. Furthermore, there might have been a survivor bias favoring the late CABG group, because patients who died early could not undergo late CABG. This limitation, however, only strengthens our finding of no apparent benefit associated to routine CABG delay. Although we attempted to account for these factors through comprehensive multivariable analyses, it is possible that other unmeasured factors could also have contributed to CABG timing and also influenced outcomes. This study only performed follow-up through hospital discharge, 

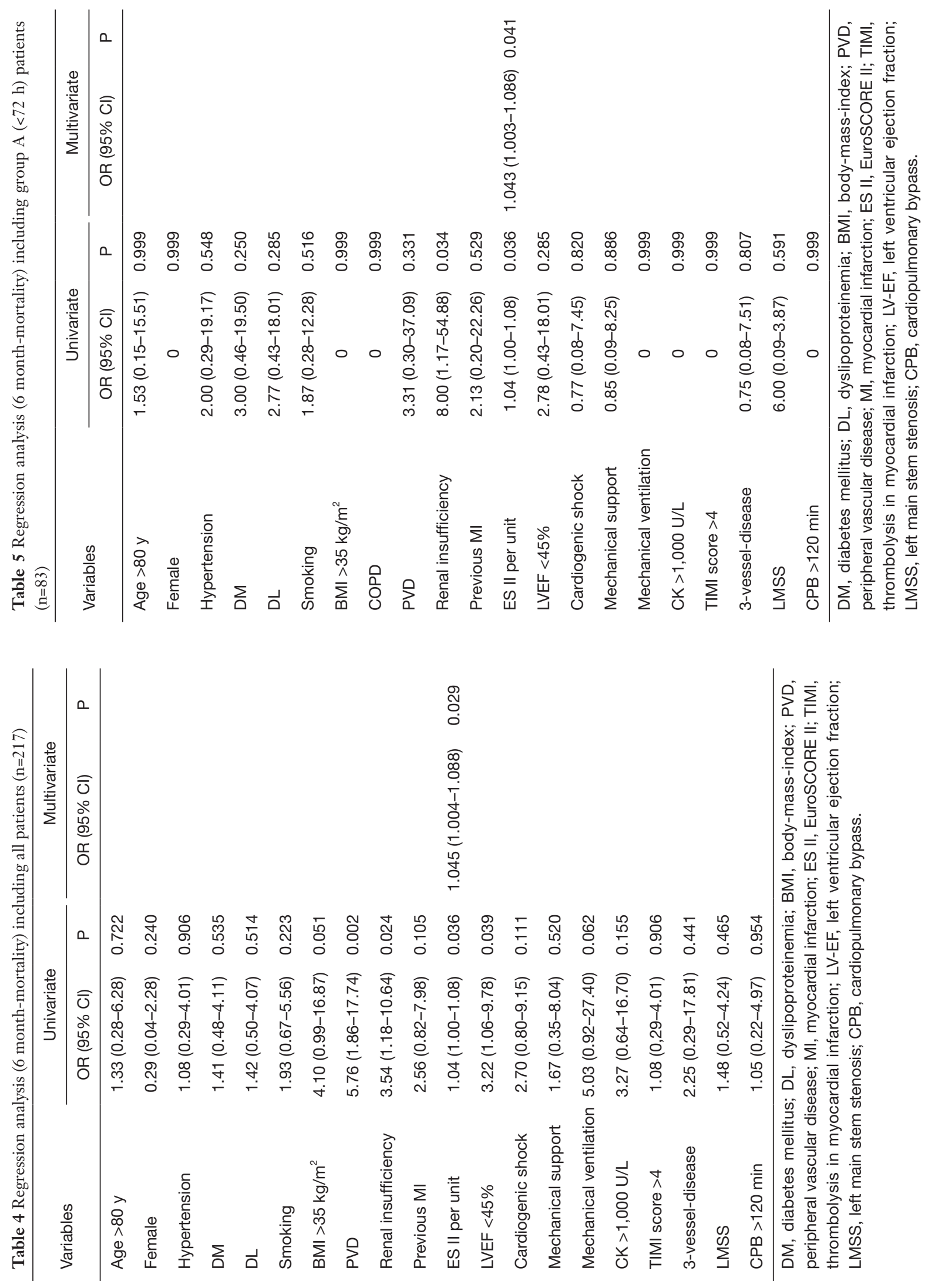
Table 6 Regression analysis (6 month-mortality) including group B (>72 h) patients ( $\mathrm{n}=134)$

\begin{tabular}{|c|c|c|c|c|}
\hline Variables & \multicolumn{2}{|c|}{ Univariate } & \multicolumn{2}{|c|}{ Multivariate } \\
\hline Age $>80 y$ & $1.33(0.28-6.28)$ & 0.722 & & \\
\hline Female & $0.29(0.04-2.28)$ & 0.240 & & \\
\hline Hypertension & $1.08(0.29-4.01)$ & 0.906 & & \\
\hline $\mathrm{DL}$ & $1.42(0.50-4.07)$ & 0.514 & & \\
\hline Smoking & $1.93(0.67-5.56)$ & 0.223 & & \\
\hline $\mathrm{BMI}>35 \mathrm{~kg} / \mathrm{m}^{2}$ & $4.10(0.99-16.87)$ & 4.095 & & \\
\hline COPD & 0 & 0.999 & & \\
\hline Previous MI & $2.56(0.82-7.98)$ & 0.105 & & \\
\hline ES II per unit & $1.04(1.01-1.07)$ & 0.032 & 1.032 (1.001-1.063) & 0.047 \\
\hline LVEF <45\% & $3.22(1.06-9.78)$ & 0.039 & & \\
\hline Cardiogenic shock & $2.70(0.80-9.15)$ & 0.111 & & \\
\hline Mechanical support & $1.67(0.35-8.04)$ & 0.520 & & \\
\hline Mechanical ventilation & $5.03(0.92-27.40)$ & 0.062 & & \\
\hline $\mathrm{CK}>1,000 \mathrm{U} / \mathrm{L}$ & $3.27(0.64-16.70)$ & 0.155 & & \\
\hline TIMI score $>4$ & $1.08(0.29-4.01)$ & 0.906 & & \\
\hline
\end{tabular}

DM, diabetes mellitus; DL, dyslipoproteinemia; BMI, body-mass-index; PVD, peripheral vascular disease; MI, myocardial infarction; ES II, EuroSCORE II; TIMI, thrombolysis in myocardial infarction; LV-EF, left ventricular ejection fraction; LMSS, left main stem stenosis; CPB, cardiopulmonary bypass.

and additional study is needed to correlate findings with longer-term outcomes up to 6 months and beyond. As well, a broader comparison group including the patient treated percutaneously also at different time points to find out which timing is optimal for both surgical and interventional strategies.

\section{Conclusions}

The ideal time point of CABG in the setting of acute MI remains controversial. Although short MI-to-CABG intervals are associated to more challenging surgery, it has to be emphasized that long intervals place post-infarct patients at risk for further adverse cardiac events, which could be fatal. The timing of surgery should consider a balance between the risks and the benefits and focus on multi-organ optimization of the patient.

\section{Acknowledgments}

None.

\section{Footnote}

Conflicts of Interest: The authors have no conflicts of interest to declare. 
Ethical Statement: The authors are accountable for all aspects of the work in ensuring that questions related to the accuracy or integrity of any part of the work are appropriately investigated and resolved. The local institutional review board approved the study (No. 1638-2012).

\section{References}

1. Mathers CD, Boerma T, Ma Fat D. Global and regional causes of death. British Medical Bulletin 2009;92:7-32.

2. Lee $\mathrm{DC}, \mathrm{Oz} \mathrm{MC}$, Weinberg $\mathrm{AD}$, et al. Appropriate timing of surgical intervention after transmural acute myocardial infarction. J Thorac Cardiovasc Surg 2003;125:115-9; discussion 119-20.

3. Lee $\mathrm{DC}, \mathrm{Oz} \mathrm{MC}$, Weinberg $\mathrm{AD}$, et al. Optimal timing of revascularization: transmural versus nontransmural acute myocardial infarction. ATS 2001;71:1197-202; discussion 1202-4.

4. Voisine P, Mathieu P, Doyle D, et al. Influence of time elapsed between myocardial infarction and coronary artery bypass grafting surgery on operative mortality. Eur J Cardiothorac Surg 2006;29:319-23.

5. Davierwala PM, Verevkin A, Leontyev S, et al. Does Timing of Coronary Artery Bypass Surgery Affect Early and Long-Term Outcomes in Patients with Non-STSegment-Elevation Myocardial Infarction? Circulation 2015;132:731-40.

6. Roe MT, Messenger JC, Weintraub WS, et al. Treatments, Trends, and Outcomes of Acute Myocardial Infarction and Percutaneous Coronary Intervention. J Am Coll Cardiol 2010;56:254-63.

7. Developed with the special contribution of the European Association for Percutaneous Cardiovascular Interventions (EAPCI), Kolh P, Authors/Task Force Members, et al. Guidelines on myocardial revascularization: The Task Force on Myocardial Revascularization of the European Society of Cardiology (ESC) and the European Association for Cardio-Thoracic Surgery (EACTS). Eur Heart J 2010;31:2501-55.

8. Authors/Task Force Members, Hamm CW, Bassand JP, et al. ESC Guidelines for the management of acute coronary syndromes in patients presenting without persistent ST-segment elevation: The Task Force for the management of acute coronary syndromes (ACS) in patients presenting without persistent ST-segment elevation of the European Society of Cardiology (ESC). Eur Heart J 2011;32:2999-3054.

9. Authors/Task Force Members, Steg PG, James SK, et al. ESC Guidelines for the management of acute myocardial infarction in patients presenting with STsegment elevation: The Task Force on the management of ST-segment elevation acute myocardial infarction of the European Society of Cardiology (ESC). Eur Heart J 2012.33:2569-619.

10. Hagl C, Khaladj N, Peterss S, et al. Acute treatment of ST-segment-elevation myocardial infarction: is there a role for the cardiac surgeon? Ann Thorac Surg 2009;88:1786-92.

11. Hong S, Youn YN, Yi G, et al. Long Term Results of STSegment Elevation Myocardial Infarction versus NonST-Segment Elevation Myocardial Infarction after OffPump Coronary Artery Bypass Grafting: Propensity Score Matching Analysis. J Korean Med Sci 2012;27:153.

12. Senanayake EL, Howell NJ, Evans J, et al. Contemporary outcomes of urgent coronary artery bypass graft surgery following non-ST elevation myocardial infarction: urgent coronary artery bypass graft surgery consistently outperforms Global Registry of Acute Coronary Events predicted survival. Eur J Cardiothorac Surg 2012;41:e87-92.

13. Sezai A, Minami K, Hata M, et al. Long-Term Results (Three-Year) of Emergency Coronary Artery Bypass Grafting for Patients With Unstable Angina Pectoris. Am J Cardiol 2010;106:511-6.

14. Sezai A, Hata M, Yoshitake I, et al. Results of Emergency Coronary Artery Bypass Grafting for Acute Myocardial Infarction: Importance of Intraoperative and Postoperative Cardiac Medical Therapy. Ann Thorac Cardiovasc Surg 2012;18:338-46.

15. Rastan AJ. Emergency Coronary Artery Bypass Graft Surgery for Acute Coronary Syndrome: Beating Heart Versus Conventional Cardioplegic Cardiac Arrest Strategies. Circulation 2006;114:I477-85.

16. Khaladj N, Bobylev D, Peterss S, et al. Immediate surgical coronary revascularisation in patients presenting with acute myocardial infarction. J Cardiothorac Surg 2013;8:167.

17. Osawa H, Fujimatsu T. Emergency Coronary Artery Bypass Grafting for Left Main Shock Syndrome. Ann Thorac Cardiovasc Surg 2011;17:565-9.

18. Wright RS, Anderson JL, Adams CD, et al. 2011 ACCF/AHA Focused Update of the Guidelines for the Management of Patients With Unstable Angina/NonST-Elevation Myocardial Infarction (Updating the 2007 Guideline). J Am Coll Cardiol 2011;57:1920-59.

19. Serruys PW, Morice MC, Kappetein AP, et al. Percutaneous coronary intervention versus coronary-artery bypass grafting for severe coronary artery disease. $\mathrm{N}$ Engl 
J Med 2009;360:961-72.

20. Weintraub WS, Grau-Sepulveda MV, Weiss JM, et al. Comparative effectiveness of revascularization strategies. N Engl J Med 2012;366:1467-76.

21. Parikh SV, de Lemos JA, Jessen ME, et al. Timing of inhospital coronary artery bypass graft surgery for non-STsegment elevation myocardial infarction patients results from the National Cardiovascular Data Registry ACTION Registry-GWTG (Acute Coronary Treatment and Intervention Outcomes Network Registry-Get With The Guidelines). JACC Cardiovasc Interv 2010;3:419-27.

Cite this article as: Rojas SV, Trinh-Adams ML, Uribarri A, Fleissner F, Iablonskii P, Rojas-Hernandez S, Ricklefs M, Martens A, Rümke S, Warnecke G, Cebotari S, Haverich A, Ismail I. Early surgical myocardial revascularization in nonST-segment elevation acute coronary syndrome. J Thorac Dis 2019;11(11):4444-4452. doi: 10.21037/jtd.2019.11.08
22. Navarese EP, Gurbel PA, Andreotti F, et al. Optimal timing of coronary invasive strategy in non-ST-segment elevation acute coronary syndromes: a systematic review and meta-analysis. Ann Intern Med 2013;158:261-70.

23. Ngaage DL, Sogliani F, Tang A. Early and late prognostic implications of coronary artery bypass timing after myocardial infarction. Eur J Cardiothorac Surg 2013;43:549-54.

24. Grant SW, Hickey GL, Dimarakis I, et al. Performance of the EuroSCORE models in emergency cardiac surgery. Circ Cardiovasc Qual Outcomes 2013;6:178-85. 